\title{
Investigating Language Learning Strategies of EFL Children for the Development of a Taxonomy
}

\author{
Esim Gürsoy \\ ELT Department, Uludag University \\ E-mail: esimgursoy@yahoo.com
}

The article is derived from an unpublished doctoral dissertation by Gürsoy, E. (2004).

\begin{abstract}
As a still growing area, Language Learning Strategies (LLS) research needs to expand so that it covers different contexts and age groups. Previous research shows that most of LLS research is conducted in ESL contexts and the majority looked into strategies of adolescents and adults. Consequently, strategy taxonomies as well as the inventories developed so far, comprise this context and age group mentioned. Thus, the current study investigates children's language learning strategies in an EFL context. Data is collected from 54 children via methodological triangulation through, a semi-guided questionnaire, task-based interviews, observations during students' task performance, field notes kept during task-based interviews, think- aloud protocols for reading and writing skills, classroom observations, and general interviews conducted according to the results of the semi-guided questionnaire. Triangulation in location is also applied. As a result of the study, LLS of children are identified and then organized as a taxonomy upon taking Oxford's (1990) classification as a basis.
\end{abstract}

Keywords: Language learning strategies, Children, Strategy taxonomy, Young learners

\section{Introduction}

Recently, many countries in Europe and Asia have increased their efforts to teach English as a foreign (EFL) or second language (ESL) at the primary school level (Tucker, 2001). Despite the efforts shown for the past 20 years to teach EFL or ESL to children, the research literature on the topic is still embryonic (Cameron, 2001).

During the 1970s and 1980s the interest in the learner him/herself grew and this directed classroom focus from teacher-centered approaches to student-centered ones (Rubin, 1987; Zhao, 2009). Due to this shift, interest in the learner autonomy has also grown with the assumption that students need to take responsibility for their own learning (Rubin, 1987; Zhao, 2009). One of the ways to enhance learner autonomy and create student-centered learning environment is through the use of language learning strategies (LLS).

Language Learning Strategies (LLS) has been investigated since the late 1970s and early 1980s and started with the identification of LLS of good language learners. It has been observed by a number of language educators that some learners become more successful in the language learning process, whereas, some others fail to reach such success (Rubin, 1975). At this point, Rubin (1987) mentions that the literature on LLS assumes that these successful learners use particular cognitive and metacognitive behavior. Thus, their success is attributed to the use of such cognitive and metacognitive processes. The differences between learners become clear when they share the same L1 background, learn the same target language under the same circumstances, and in the same context. It is thought that if the strategies of successful language learners can be identified it would be possible to teach them to less successful learners and, thus, increase their learning outcomes.

Consciously or unconsciously LLS are used by all language learners, including children, when learning another language. However, research so far on language learning strategies mostly focused on adolescents and adults (See, for instance, Griffiths, 2007) and little is known about the strategies of young learners. Teaching a second language to children has been practiced in countries such as the USA, Canada, and/or Australia due to their immigrant populations. Hence, limited studies on children's LLS focused on children in such ESL contexts. The research mostly investigated the strategies of bilingual children, children in immersion classrooms, and children in ESL contexts (See, Purdie and Oliver, 1999; Padron and Waxman, 1988; Chamot and El-Dinary, 1999). The growing tendency to teach EFL to children is a triggering factor to investigate language learning behaviors of children in such contexts in addition to those in immersion and ESL contexts.

The research literature on children's LLS is limited in terms of the types of strategies that are investigated. The previous research mostly focused on a single strategy type (cognitive, metacognitive etc.) or investigated strategy use within a specific skill (such as reading, writing etc.) Therefore, a more comprehensive study is necessary to investigate children's strategy use within all strategy types and language skills.

Furthermore, since the majority of LLS research has focused on learners in adolescence and adulthood (see, 
Halbach, 2000; Sheorey, 1999; Green and Oxford, 1995; Griffiths and Parr, 2001) there is a need to develop a strategy taxonomy for a younger age group. Although it is possible that children might use similar strategies to adults and adolescents, we cannot presuppose that adult LLS are also applicable to children. This is because data for these taxonomies are collected from older age groups. Therefore, there is also a need to develop a taxonomy for children with data gathered from children. This would enable the educators and the researchers to identify the differences between adults and children, and would enable the methodologists, as well as the classroom teachers to develop appropriate methodologies for their learner group by becoming aware of their capabilities and limitations, both cognitive and affective. This, in turn, will help developing suitable strategy training.

\section{Background}

\subsection{What are learning strategies?}

Due to increasing attention to student-centered instruction and the student him/herself, learning strategies rapidly gained importance (Nyikos \& Oxford, 1993). A strategy can be described as a mental procedure that is used to promote learning and which sometimes can be observed as an overt activity (Chamot \& El-Dinary, 1999). Oxford (1990) defines learning strategies as "operations employed by the learner to aid the acquisition, storage, retrieval, and use of information" (p. 8). Weinstein and Mayer (1986) argue that the goal of a learning strategy might be to affect the way the learner "selects, acquires, organizes, integrates" (p. 315) new information or to affect motivational or affective states of the learner.

Initial strategy research investigated the characteristics of the good language learner and identified strategies that effective language learners use while learning a second language (O'Malley, Chamot, Stewner-Manzanares, Russo, and Küpper, 1985a; Rubin, 1975; Rubin, 1987; O'Malley and Chamot, 1990). Following intervention studies, conducted in first and second language contexts, taught effective learning strategies (Chamot \& Küpper, 1989).

Strategy research to date has shown that all language learners use some type of strategies (Hong-Nam and Leavell, 2006), yet the frequency, variety, and the choice of strategies show variation among learners (Chamot and Küpper, 1989). However, Purdie and Oliver (1999) cautions practitioners when applying results of language learning strategy research conducted with adults and adolescents to children. Further, they argue that children differ from adults and adolescents psychologically and socially as well as their approach to language learning. Consequently, it is necessary to extend strategy research to address the issue of age (Oxford and Crookall, 1989; O'Malley and Chamot, 1990) and to children at different contexts

\subsection{How are children different from adults?}

Children can learn a language other than their mother tongue in various situations depending on the amount and type of exposure to the target language. The current study focuses on the foreign language context in formal environments (schools).

In EFL environments, mostly it is the teachers' responsibility to provide learning opportunities and exposure for their students. In addition, teachers also need to help their learners to facilitate their learning process. Language learning strategies are one way to do this. Learning about students' current strategies and teaching new ones facilitates the learning of L2. Moreover, strategy use improves performance of the learners and leads them to regulate their own learning (McMullen, 2009). Therefore, identification of learner strategies at different age groups is one of the vital points that need consideration in the field of LLS.

Understanding of the differences of children from adults is crucial in the investigation of the strategy use. Unlike adults, children are enthusiastic and talkative; however, at the same time they lose concentration and motivation easily (Moon, 2000). Children have limited world knowledge and experience. In addition, they are still at the earlier stages of their cognitive development because they do not have access to metalanguage as do older learners (Moon, 2000). Due to these differences, it is possible that children use different strategies from adults.

Most of the strategy research so far has investigated learners above elementary school. Limited number of studies concerning the strategy use of elementary school children mostly focused on strategy use in L1. It can be said that success has been achieved in studies where children use L1 learning strategies (Chamot and El-Dinary, 1999). The rest of the research on children's language learning strategies either focused on a single strategy type and/or skill or tried to describe strategies used by bilingual children (See, Padron and Waxman,1988; Purdie and Oliver, 1999). Chamot and El-Dinary (1999) took research on children's language learning strategies one step further and investigated learning strategies of children in immersion classes. However, there is still a gap in the literature to be filled. Further studies are necessary to understand and learn about the strategy use of children in formal EFL contexts. 


\subsection{Language Learning Taxonomies}

Efforts to identify the characteristics of the good language learner showed that language learners apply learning strategies and that it is possible to describe and classify them (O'Malley and Chamot, 1990). As a result, several researchers have developed various Language Learning Taxonomies some of which are worth mentioning. One of these is Rubin's (1981; see also, O'Malley et al. 1985a; and O'Malley, Chamot, Stewner-Manzanares, Küpper, and Russo, 1985b) strategy classification. Accordingly, Rubin (1981) identified two primary categories: strategies that affect learning directly and indirectly. Rubin's classification of direct strategies includes clarification/verification, monitoring, memorization, guessing/inductive inferencing, deductive reasoning, and practice (O'Malley and Chamot, 1990). Indirect strategies are creating opportunities for practice and production tricks.

Another strategy classification was developed by Bialystok (1978), which was born out of her model of second language learning. Accordingly, language learning strategies indicate optional relationships between the elements of her model. Her classification includes four categories: formal practicing, functional practicing, inferencing, and monitoring. According to her model, learning strategies are defined as "optional means for exploiting available information to improve competence in a second language" (Bialystok, 1978, p. 71).

O'Malley and Chamot (1990), grouped language learning strategies under three broad categories. The first group of strategies is metacognitive strategies, which consists of seven strategies grouped under three strategy sets: planning, monitoring and evaluation. The second group is called cognitive strategies and consists of fourteen strategies: resourcing, repetition, grouping, deduction, imagery, auditory representation, keyword method, elaboration, transfer, inferencing, note taking, summarizing, recombination, and translation. The last group of strategies is social strategies named as social mediation or social affective strategies. In this group there are two strategies: question for clarification and cooperation (Chamot, 1993).

A more complicated strategy classification is developed by Oxford (1990). Through extensive review of the literature, Oxford (1990) developed a language learning strategy scheme that is the most appreciated and used so far. She initially groups strategies under two main categories as direct and indirect strategies.

Direct strategies are those that involve direct use of language, as well as affect language learning directly, whereas indirect strategies support language learning (Oxford, 1990; Hsiao and Oxford, 2002). Each major category consists of three strategy groups: memory, cognitive, and compensation strategies under direct strategies and metacognitive, affective and social strategies under indirect strategies. These strategy groups are composed of 19 strategy sets. Within the direct strategies, memory strategies have four sets: creating mental linkages, applying images and sounds, reviewing well, and employing action. The strategy sets in cognitive strategies are: practicing, receiving and sending messages, analyzing and reasoning, and creating structure for input and output. Compensation strategies have two sets: guessing intelligently and overcoming limitations in speaking and writing. Within indirect strategies, metacognitive strategies have three strategy sets; centering your learning, arranging and planning your learning and evaluating your learning. Lowering your anxiety, encouraging yourself, and taking your emotional temperature are the sets under affective strategies. Finally, social strategies include asking questions, cooperating with others and empathizing with others. As a whole, Oxford's strategy system includes 62 strategies under these strategy sets. Since this is the richest and the most detailed system of categorization, current study uses it as a basis.

Due to different learning characteristics and social and psychological development it would be misleading to adopt strategy research so that it includes young learners. First of all, it is possible that children use different strategies than adults and/or adolescents. This variation could be in the number and the type of strategies they use. Hence, it is indispensable to extend strategy research to find out any possible differences and/or similarities between children and adults/adolescents in their use of language learning strategies. Secondly, it is argued that language learning strategies influence the rate and level of second language acquisition of children (O'Malley \& Chamot, 1990). To improve children's language learning process, it is prominent to investigate their language learning strategies and train them to use effective strategies to enhance their development in rate and level. Thus, it is equally important to identify the types of strategies that children prefer using to integrate strategy training into their learning. Finding out children's strategies would enable the teachers and educators to; develop new methodologies or expand existing ones, find effective ways of teaching, understand children's choice of strategies, design lessons according to children's needs, facilitate language learning process, implement strategy training to help them learn new and effective strategies, and create autonomous learners.

\subsection{Purpose of the Study}

As seen from the literature, strategies of elementary school children were investigated either in L1 or in ESL contexts or they focused on single strategy type or strategies used while learning a single skill. There is a need for 
a more comprehensive study that investigates all strategy types and their use in various skills. Hence, there is still a gap to be filled. In addition, there is also a need for studies conducted in EFL contexts to identify strategy use and strategy choices alternating according to the setting, culture, and language background.

The present study aims to report on the detailed data collection process to identify the language learning strategies of children at third, fourth and fifth grades in two private schools in Turkey. In addition, it aims to develop a taxonomy for Language Learning Strategies of this group of learners by using Oxford's (1990) extensive classification as a basis.

\subsection{The Significance of the Study}

This study is unique in that it inquires language learning strategies of young learners as a whole without any specific concentration on a specific strategy type such as memory, cognitive, compensation, metacognitive, social, and affective, or specific strategy or strategies within a specific strategy type such as repeating and translating strategies under cognitive strategies. It will not be limited to certain language skills such as reading or listening. In addition, an LLS taxonomy for children will enable a comparison of strategy use between adults and children.

\subsection{Research Questions}

The study will try to answer the following questions:

1) What are the language learning strategies of children at third, fourth and fifth grades?

2) Can these strategies be grouped so that a taxonomy for children's LLS is developed?

3) Does the LLS taxonomy for children differ from the one that was developed for adults?

4) Do children use all strategy sets and groups mentioned in the literature?

\section{Methodology}

\subsection{Subjects}

For this research a total of 54 students from third, fourth and fifth grades in two private schools were selected for investigation. Both schools and the classes were randomly selected. 17 third grade, 14 fourth grade and 23 fifth grade students contributed to the study. One of the reasons to conduct this study only in private schools is due to the fact that the language learning curriculum in private and government schools differ in Turkey. Therefore, the results of the study can only be generalized to children who have similar learning opportunities. For instance, foreign language education in government schools starts in the fourth grade, whereas in private schools it begins in the first grade or pre-school. In addition, the amount of time spent for language instruction in most private schools is 10 hours a week or more, however, in government schools it is three hours a week. Another difference is the language learning opportunities that these two types of schools provide for their students. For instance, the classes are more crowded in government schools and they are not technologically well-equipped. The children in private schools have more exposure to L2 which enables students to use and practice the target language more often than their peers in government schools. In most of the government schools students lack the opportunity to develop listening and speaking skills due to few hours of English lessons, crowded classrooms, and the absence of technological equipment; whereas private schools follow a whole language approach. As the current study aimed a more comprehensive investigation on LLS of children in EFL contexts, the researcher limited the study to learners who have more or less equal opportunities to develop all four language skills.

Third, fourth and fifth grade students are in concrete operations period according to Piaget's developmental stages. According to Piaget, children between seven and 11years of age form their conclusions by depending on logic or logical rules, but cannot develop hypothetical thinking. Although the borders of cognitive stages are flexible, current research relies on the generalization of the characteristics of children during Piaget's cognitive development stages.

There are several reasons to collect data from third, fourth and fifth grade students but not from first and second graders. First of all, the characteristics of first and second grade students, who are between the ages of seven and eight, are different from third, fourth and fifth grade students in terms of their cognitive abilities, and would require the use of different data collection techniques. In addition, attention span of third, fourth and fifth graders are longer when compared to first and second graders. While first and second grade students are developing reading ability, third, fourth and fifth grade students have developed reading as well as writing ability. Moreover, affectively, fear and anxiety are the dominant feelings of the younger children, whereas third, fourth and fifth grade students have lower affective filters (Gürkan \& Gökçe, 1999). Affective development of children is very important when collecting data. If children become too anxious or afraid about the process or during the process, the validity of the results will be negatively affected. 


\subsection{Data Collection}

Data collection needs careful planning and requires attention when working with children. This is due to the difficulties that might be faced during the process. Accordingly:

1) Children may react differently to various data collection methods because of their age when compared to adults.

2) They can get bored easily and lose concentration during the data collection process.

3) If they are not interested in what the researcher is doing and why they have to be a part of it, they might refuse contributing to the process.

4) Although it is a serious process, children may not think it is and respond in ways other than the researcher has expected.

These and possible other drawbacks might cause teachers and researchers to resist or hesitate collecting data from children. Yet, for a research of this importance it is essential to find out the efficient methods of data collection to elicit necessary information on LLS of children.

There are various research perspectives. According to Marton (1981), a distinction needs to be made when researching what people actually do and what they think they do. This distinction points out the possible difference between what people actually do and what they think they are doing, which emphasizes a variety in research perspectives. Marton (1981) calls the former as first-order research and the latter as second-order research. He defines these two research perspectives as follows: "In the first, and by far most commonly adopted perspective, we orient ourselves towards the world and make statements about it. In the second perspective, we orient ourselves towards people's ideas about the world (or their experience of it)" (Marton, 1981, p. 178).

However, one shouldn't get the idea that first-order equate being objective and the second-order being subjective since they "are based on assigning meanings to what is observed and experienced" (Freeman, 1998, p. 66). These two orientations enable the researcher to organize his/her research questions and decide ways to collect data to answer them.

The current study uses a methodological triangulation since there is no single method that proved to be useful when collecting data from children. The variety in data collection methods enables us to receive both first-order and second-order perspectives. Through the questionnaire and the interviews, a second-order perspective was gained and observations of the interviewees during the task-based interviews and think-aloud process and the classroom observations by the researcher will provide a first-order perspective. In addition, the research makes a triangulation in location (collecting data from various locations).

Through observations it was possible to see what children actually do while learning. Of course, the results of this method are limited to those strategies that are only observable. Others that cannot be observed were elicited by other data collection methods such as task-based interviews and a semi-guided, open-ended questionnaire.

Collecting data from verbal reports such as interviews is said to be beneficial since they provide direct evidence about invisible processes. In addition, they provide rich data and enable the researcher to explore and identify cognitive processes. However, they also have a disadvantage since they only provide information about the learners' conscious strategies (Hayes and Flower, 1983).

Unlike observations, through interviews it is possible to gather information from personal insights that are not possible to gather through observations. Yet, their disadvantage is that a considerable amount of time is needed on the part of the teachers and the students.

Verbal reports can also be gathered by retrospective methods. Retrospection is done after the investigated event has taken place. This type of data collection has also drawbacks. First, the fact that there is a certain amount of time between the event and the reporting may cause to receive unreliable data. Second, it is also possible that if subjects are informed that they are going to provide a retrospective account, their task performance might be influenced (Nunan, 1986). Reliability of retrospective data collection can be enhanced if retrospection is done right after the event occurred. In addition, it is also beneficial not to inform the subjects that they will be asked to retrospect afterwards (Nunan, 1986).

Oxford and Crookall (1989) argue that multiple methods, both qualitative and quantitative, need to be used to validate the data. Thus, data is collected by using five different methods. First, an open-ended and semi-guided questionnaire; second, task-based interviews; third, observations during task-based interviews; fourth, general interviews designed according to the results of the questionnaire, and finally, classroom observations are used to 
gather information about the subjects' language learning strategies. They were first piloted on 41 students and necessary changes were made.

According to the results of the pilot study, an open-ended, semi-guided questionnaire proved to be the most efficient method in eliciting strategies, since the highest number of strategies (33) was gathered as a result of this technique (interview: 23 and observation: 7). This might be because that the questionnaire was semi-structured in nature. Thus, it directed students to complete each statement or answer questions. For instance, for an incomplete statement as: 'If I come across an unknown vocabulary while reading, I ......' students were asked to write what they usually do in such conditions. The questions and the statements were designed so that they do not direct students to answer in a certain way or give out some strategies. Yet, showing students what to write about facilitated the process and enabled them to focus on a specific issue rather than thinking globally what they do while learning a foreign language. The questionnaire, consisting of 20 questions, was developed by taking into consideration the four skills and vocabulary and grammar learning. To prevent any language barrier, it was administered in Turkish.

Questions inquired what students do before, during and after an activity, since type of strategy and the mental processes might change according to what the learner is engaged in doing. The questionnaire was conducted on 54 students.

The task-based interviews revealed quite a large number of strategies. 15 students (five from each grade level) were randomly selected for the interviews. The think-aloud process, which is an introspective method, was used during the interviews for the reading and writing skill and each student was interviewed alone. During a think-aloud process subjects are asked to verbalize what they do and why they do it while performing a task (Nunan, 1986); therefore, this technique provides the most detailed information when compared to other techniques (Oxford \& Burry-Stock, 1995). A difference from the stimulated recall is that they do not have to reflect on what they have done previously, but verbalize what they are doing at the moment of the task. This means the limitation that comes from forgetting is eliminated. Another reason why think-aloud was chosen for reading and writing was due to the cognitive abilities of this age group. Children between seven and 11 are considered to be in Piaget's concrete operations period. Since, during reading and writing tasks the students would be able to deal with something concrete (the written material), it was thought that it would be easier to work with this kind of material. A disadvantage of the think-aloud protocols is due to its application. Since they are conducted on a one-to-one basis they require a lot of time and results are not summative (Oxford \& Burry-Stock, 1995).

Since it is sometimes difficult even for some adults to "think aloud", the students were given training before they do the real task. In addition to describing what they need to do, the researcher also exemplified a think-aloud process herself and asked the subjects to try it themselves.

For speaking and listening skills, students were interviewed right after they finished the task so that they did not have time to forget what they did. Students were interviewed in their native language in order to overcome any misunderstandings due to the limited knowledge of the FL. In the interviews they were asked about what they did during the task and why they did it. All interviews were also tape-recorded. In addition, the interviewees were observed before, during, and after they performed the tasks and field notes were kept during observation. Before students started listening, the interviewer informed them about the process. They were told that they are going to listen to a passage. After listening the first time, some comprehension questions were asked and then they were inquired about how they understood what they listened. Then they listened again and asked if they understood more the next time. After the introduction and before starting the listening task, students were observed to see if they are in some kind of preparation for the task such as taking a paper or a pen to take notes while listening, since this is a metacognitive strategy.

In the speaking skill of third grade students they were given a picture to talk about. They were observed before the task in order to investigate any strategies they use such as writing the names of the objects seen in the picture to facilitate oral production, etc. All tasks were chosen according to students' language abilities and in consultation with their language teacher. Reading and listening activities for all grades were supported by pictures. All task materials for third graders were chosen from "Skills Builder for Young Learners 1: Starters Student's Book" (Gray, 2000).

Students were also observed during the tasks. Observable strategies that they used such as taking notes, using mime or gesture, using circumlocution, synonyms, translation, switching to mother tongue, were noted. Similarly, after they performed the tasks student behavior such as summarizing, reading, reviewing, or correcting their notes that they kept while listening were observed and kept as a field note. 
An additional interview was also conducted with the learners according to the answers gathered via the questionnaire. The purpose was to learn more about students' responses and clarify fuzzy descriptions and responses written in the questionnaire. Interviewees for this interview were determined according to the results of the questionnaire. Thus, a total of 45 students were interviewed to investigate certain issues that were not clearly stated in the questionnaire.

Classroom observations were used to support data gathered by other techniques. Observations were made by using a checklist developed by the researcher. Each classroom at each grade was observed for six classroom hours. A total of 18 classroom hours were spent for observation.

\section{Data Analysis}

Inductive analysis was made on the qualitative data. First the tape- recordings were transcribed. Then all the verbal data gathered from field notes, observations, interviews, semi-guided questionnaire and the transcriptions were coded. Then the categories and sub-categories were generated. Later, these codes and categories were matched. As a result, it was learned that most of the strategies fell under Oxford's strategy taxonomy. However, as it is argued by Oxford \& Crookall (1989) there is not a consensus on LLS taxonomy or on the definition of strategies. Thus, for some strategies that learners use and are not present in Oxford's (1990) taxonomy, the researcher added a new strategy set or individual strategy. In addition, some of Oxford's definitions needed to be expanded as children used similar adult strategies in different ways and purposes. In a similar study by O'Malley, et al. (1985), it is indicated that some strategies used by students did not match the strategy definitions found in the literature. Thus, O'Malley et al. (1985) developed new names for strategies they identified during the data collection process that matched the descriptions.

According to the results of the data analysis, it appeared that children use only three memory strategies which are the members of one set (creating mental linkages) and only one affective strategy. Two sets that belong to memory strategies and two sets that belong to the affective strategies were not used at all. Oxford's Memory Strategies aim to build internal associations, which require higher cognitive abilities. According to Piaget, abstract thinking develops after the age of 11 during the period of formal operations. However, subjects are nine, 10, and 11 years old. These children are at the Period of Concrete Operations and are assumed to be able to develop reasonable thinking, but not hypothetical thinking. Therefore, this might be the reason why most of the memory strategies, which require higher order cognitive skills, did not appear in the data. Also, Weinstein and Mayer (1986) support this claim by saying that "younger children are not able to effectively generate images but are able to use imagery that is provided by a teacher" (p. 319). In addition, they also argue by referring to the literature that basic rehearsal strategies such as repeating certain items to memorize new information is used more by students at fourth grade and lower grades. Thus, the results of the current study support this argument and the literature.

\section{Results and Discussion}

As a result of the data analysis, the strategies that are used by the subject group were identified and a taxonomy for language learning strategies of EFL children in Turkey is developed (see appendix). Data analysis indicated that there are some strategies as well as strategy sets that are not present in Oxford's taxonomy. Some of the new strategies that deserve specific attention are those related to pronunciation. In Oxford's taxonomy pronunciationrelated strategies are limited to practicing, but current research showed that children's strategies for pronunciation are not restricted to practicing only. For instance, they try to use native language sources to develop pronunciation. They focus on how a word is said when watching a film or listening to a passage from the tape and they try to create some connections between the meaning of the word and its pronunciation ("I think of the meaning of the new word in order to pronounce it correctly"). In addition, by using this strategy the child tries to write the pronunciation of an English word by using sounds found in Turkish ("In order to pronounce a word correctly I write it as if it is read in Turkish and read it several times"). For instance, for refrigerator the child writes 'refricireytır'. This variety signals that it is an important aspect of language for children to pronounce the target language words correctly.

Another example of child-specific strategy is seen under compensation strategies. In the open-ended, semi-guided questionnaire some children indicated that while speaking or writing if they do not know the meaning of a word in English they draw the picture of it (If I do not know the meaning of a word when writing, I draw its picture). As it can be seen the effort to continue the oral or written communication takes its place in a mostly child-specific way.

"Doing practice tests" under cognitive strategies is another new strategy, which might be specific to this subject group. In Turkey the education system is exam-oriented. Even in primary schools children take standardized tests. Therefore, this specific subject group might have considered practice tests and exercises as a good way to improve their language learning process. As from these examples it can be understood that LLS might have differences 
according to age, mother tongue, culture, and education system of the EFL country. Therefore, further research is necessary to find out such differences in different EFL contexts.

In conclusion, 17 strategies and five strategy sets are identified as new and used by EFL children in private schools in Turkey. In addition, it is found out that some of the strategies and strategy sets that are found in Oxford's (1990) taxonomy require some expansion in their definition. These are;

1) Structured Reviewing under Memory strategies

2) Analyzing Contrastively under Cognitive strategies

3) Practicing Naturalistically under Cognitive Strategies

4) Seeking Practice Opportunities under Metacognitive Strategies

5) Planning for a Language Task under Metacognitive Strategies

6) Definition of Social Strategies

The discussion of the new strategy sets and those that require expansion in their definition is the focus of another study; thus, only the answers to the research questions will be given.

The identification of the new strategies and strategy sets that are not found in Oxford's (1990) taxonomy might be an indication that these are specific strategies for the subject group. There is, of course, some possibility that some of these strategies are used by adults, but not identified by previous research. In addition, since most of strategy research was conducted in ESL contexts, some of these strategy sets such as "interacting with others" can be specific to EFL contexts. Moreover, some other can be specific to subject groups' culture and language such as "using native language sources for pronunciation".

By looking at the results the first and second research questions can be answered. The first question attempted to find out the language learning strategies of children. Accordingly, children use 46 strategies under 18 strategy sets, some of which are common to what adults use. The strategies that are identified as a result of the data collection process were later investigated to find out the strategy groups that children use. As an answer to the second question, it can be said that it is possible to develop a LLS taxonomy for children and the children's strategy preferences can be seen in the taxonomy (see appendix).

The third research question tried to inquire whether children's taxonomy differs from adults'. When examining the taxonomy it can be said that there are some differences between the two. Most of these are not major. Children's taxonomy needs some additional strategy sets and individual strategies as well as some expansion in some definitions. The different strategy preferences mostly are due to children's cognitive abilities, characteristics and differences between adults. Therefore, it can be argued that most of the new strategies and strategy sets that appeared are children-specific.

The fourth question investigated whether children used all strategy groups as mentioned in literature. Results are important in this respect. Although it seems that children use all strategy groups (memory, cognitive, compensation, metacognitive, affective, and social) only one memory and one affective strategy is in children's strategy repertoire. In addition, only memory strategy that is used is a new strategy that did not appear in the literature. That is, none of the memory strategies listed in the literature were used by the subjects of the present study, which is an important point.

The affective strategy "Taking Risks Wisely" is the only one used and identified through the data collection process. The reason why only this, but not the others were identified might be because children have low affective filter than adults and adolescents and that they attempt to take risks when learning the language. Thus, they tolerate being incorrect better than adults. This difference between children and adults was mentioned in the literature as Moon (2000) claimed that contrary to adults, children do not inhibit themselves when talking in a new language.

In addition, there are some strategy sets that none of the strategies under them were used. In Memory Strategies for instance, "Creating Mental Linkages" (except the new strategy added to this set), "Applying Images and Sounds", "Reviewing Well", and "Employing Action" were not used. In Affective Strategies "Lowering your Anxiety", "Taking your Emotional Temperature"; and finally, in Social Strategies "Empathizing with Others" were other strategy sets that were not used by children.

As a result, it can be said as an answer to the fourth research question that children did not use all of the strategy sets mentioned in the literature. With an exception of two strategy groups (memory and affective), the subjects used many of the strategies identified in the literature and, in fact, used additional ones that are not mentioned before. 


\section{Conclusions and Implications:}

As one of the purposes of the present study is to report on the ways to collect data from children by using different data collection methods, the research identifies the advantages and disadvantages of each method by taking children's characteristics into consideration. The detailed report on the data collection procedures is hoped to shed some light into future research on children. Since there is no single method that is proved to be adequate or valid for data collection from children, it can be said that using multiple methods increases the validity of the findings.

The research results indicate that children differ from adults and adolescents in terms of their strategy use. The differences are due to children's cognitive abilities and social and emotional development. Other differences in the strategy preferences might be dependent on the L1 background of children, culture and education system of the EFL country. Since the data is gathered only from Turkish EFL children in private primary schools, further research in different EFL settings is necessary for the generalizability of the findings. However, the research is significant in that it is the first attempt to investigate EFL children's language learning strategies in a specific formal environment.

The taxonomy is valuable for language teachers in similar contexts to understand their child language learners' strategies and to provide strategy training to help them become autonomous. In addition, it increases teachers' awareness about the types of strategies that children use. As indicated earlier, strategies can be taught. The taxonomy can be used to provide such training.

It is important that future research focus on developing a language learning strategy inventory for children. Such an inventory would facilitate the identification of children's strategy use with similar opportunities in similar settings.

The present study aimed to fill a gap in strategy research literature by focusing on EFL children in Turkey. However, research related to children's language learning strategies is still in its infancy. As the starting age to learn a foreign language is reduced, additional studies need to be conducted on child FL learners.

\section{References}

Bialystok, E. (1978). A theoretical model of second language learning. Language Learning, 28, 69-83.

Cameron, (2001). Teaching languages to young learners. UK: Cambridge University Press.

Chamot, A. U. (1993). Student responses to learning strategy instruction in the foreign language classroom. Foreign Language Annals, 26, 308-321.

Chamot, A. U. \& El-Dinary, P. B. (1999).Children's learning strategies in Language immersion Classrooms. The Modern Language Journal, 83, 319-337.

Chamot, A. U. \& Küpper, L. (1989). Learning strategies in foreign language instruction. Foreign Language Annals, 22, 13-24.

Freeman, D. (1998). Doing teacher research: From inquiry to understanding. Canada: Heinle \&Heinle.

Gray, E. (2000). Skills builder for young learners: 1 Starters student's book. UK: Express publishing.

Green, J. M. and Oxford, R. L. (1995). A closer look at learning strategies, L2 proficiency, and gender. TESOL Quarterly, 29, 261-293.

Griffiths, C. (2007). Language learning strategies: Students' and teachers' perceptions. ELT Journal, 61, 91-99.

Griffiths, C. and Parr, J. M. (2001). Language-learning strategies: Theory and perception. ELT Journal, 53, $247-54$.

Gürkan, T. \& Gökçe, E.(1999). Türkiye'de ve çeşitli ülkelerde ilköğretim: Program, öğrenci, ögrretmen. Ankara: Siyasal Kitabevi.

Gürsoy, E. (2004). A study in identifying children's language learning strategies and developing a children's inventory for language learning strategies (CHILLS). Unpublished doctoral dissertaion, Eskisehir Anadolu University the Institute of Educational Sciences, Turkey.

Halbach, A. (2000). Finding out about students' learning strategies by looking at their diaries: A case study. System, $28,85-96$.

Hayes, J. R. and Flower, L. (1983). Uncovering cognitive processes in writing. In P. Mosenthal et al. (eds), Research in writing: Principles and Methods. New York: Longman, 207-220. 
Hong-Nam, K. and Leavell, A. G. (2006). Language learning strategy use of ESL students in an intensive English learning context. System, 34, 399-415.

Hsiao, T. Y. and Oxford, R. L. (2002). Comparing theories of language learning strategies: A confirmatory factor analysis. The Modern Language Journal, 86, 368-383.

Marton, F. (1981). Phenomenography: Describing conceptions of the world around us. Instructional Science, 10, 177-200.

McMullen, M. G. (2009). Using language learning strategies to improve the writing skills of Saudi EFL students: Will it really work?. System, 37, 418-433.

Moon, J. (2000). Children learning English. China: Macmillan Heinemann.

Nunan, D. (1986). Research methods in language learning. UK: Cambridge University Press.

Nyikos, M. \& Oxford, R. (1993). A factor analytic study of language-learning strategy use: Interpretation from information-processing theory and social psychology. The Modern Language Journal, 77, 12-22.

O’Malley, J. M., Chamot, A. U., Stewner-Manzanares, G., Rocco, R. \& Küpper, L., (1985a). Learning strategy applications with students of English as a second language. TESOL Quarterly, 19, 557-584.

O’Malley, J. M., Chamot, A. U., Stewner-Manzanares, G., Küpper, L., \& Rocco, R. (1985b). Learning strategies used by beginning and intermediate ESL students. Language Learning, 35, 21-46.

O'Malley, J. M. and Chamot, A. U. (1990). Learning strategies in second language acquisition._UK: Cambridge University Press.

Oxford, R. L. (1990). Language learning strategies: What every teacher should know?. USA: Heinle and Heinle Publishers.

Oxford, R. L. \& Burry-Stock, J. A. (1995). Assessing the use of language learning strategies worldwide with the ESL/EFL version of the strategy inventory for language learning (SILL). System, 23, 1-23.

Oxford, R. L. \& Crookall, D. (1989). Research on language learning strategies: Methods, findings and instructional issues. The Modern Language Journal, 73, 404-419.

Padron, N. Y. \& Waxman, H. C. (1988). The effects of ESL students'perceptions of their cognitive strategies on reading achievement. TESOL Quarterly, 22, 146-150.

Purdie, N. and Oliver, R. (1999). Language learning strategies used by bilingual school-aged children. System, 27, 375-388.

Rubin, J. (1975). What the good language learner can teach us. TESOL Quarterly, 9, 41-51.

Rubin, J. (1981). Study of cognitive processes in second language learning. Applied Linguistics, 2, 117-131.

Rubin, J. (1987). Learner strategies: Theoretical assumptions, research history and typology. In A. L. Wenden, \& J. Rubin (Eds.), Learner strategies in language learning (pp. 15-30). UK: Prentice Hall International Ltd.

Sheorey, R. (1999). An examination of language learning strategy use in the setting of an indigenized variety of English. System, 27, 173-190.

Tucker, G. R. (2001). Age of beginning instruction. TESOL Quarterly, 35, 597-598.

Weinstein, C. E. and Mayer, R. E. (1986). The teaching of learning strategies. In . M. C. Wittrock (Ed.), Handbook of research on teaching, 3rd edition. New York: Macmillan Company.

Zhao, N. (2009). Metacognitive strategy training and vocabulary learning of Chinese college students. English Language Teaching, 2, 123-129. 
Appendix: Children's Taxonomy for Language Learning Strategies

Direct Strategies

Memory Str.s $\longrightarrow$ Creating Mental Linkages

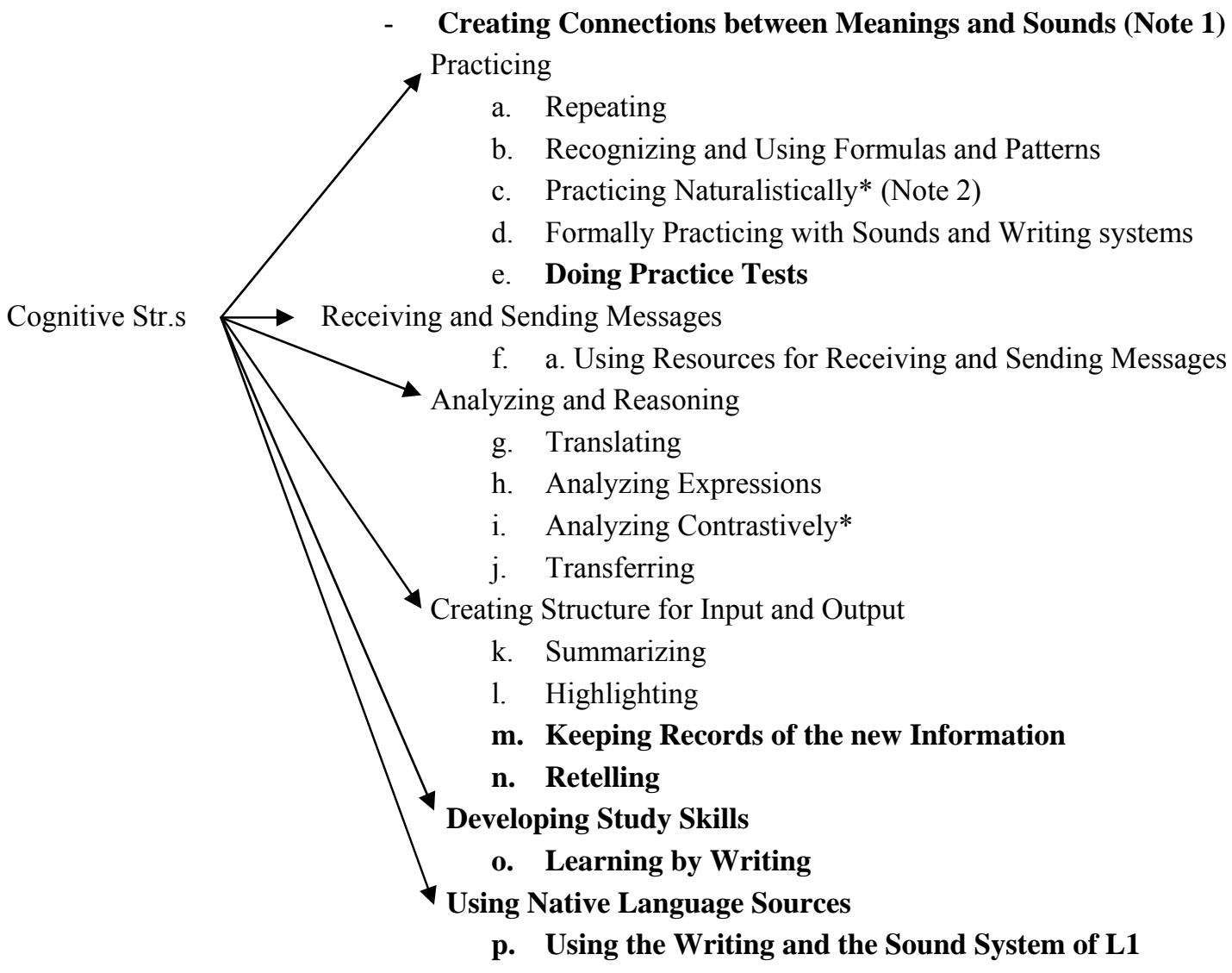

\section{Notes}

Note 1. Strategies that are written in bold are new strategies that are used by children and not found in the literature before.

Note 2. Strategies that are marked with a "*" are those that need expansion in their definition.

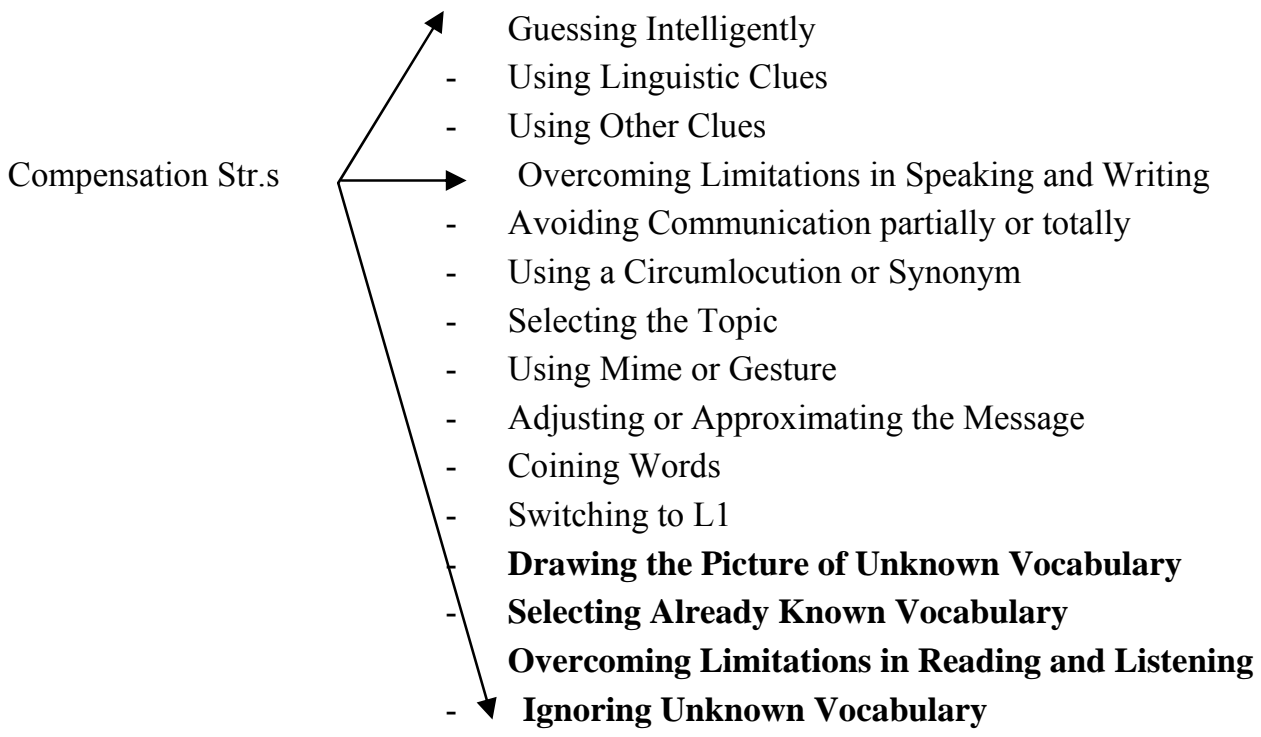




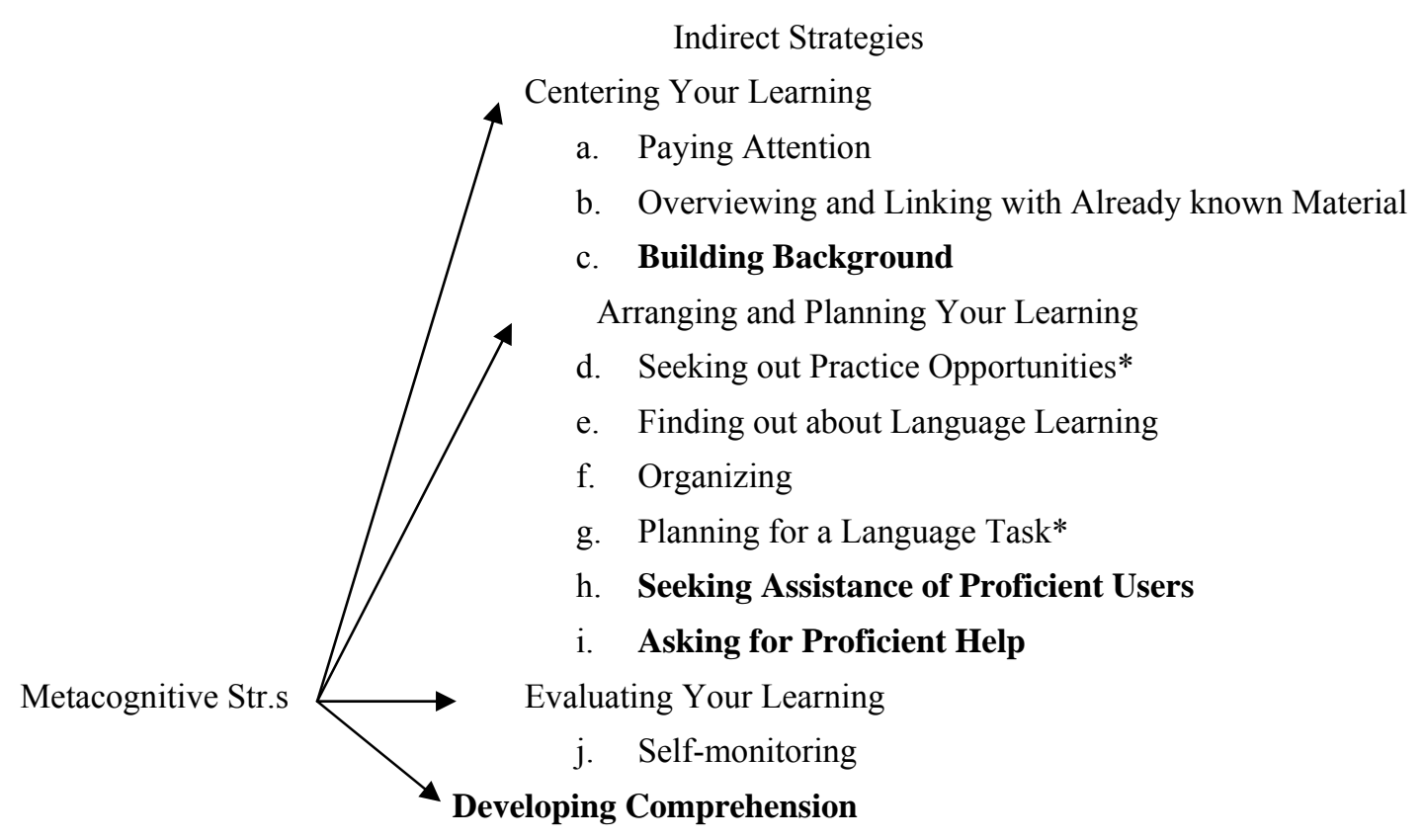

k. Self-checking Comprehension

1. Facilitating Pronunciation

Affective Str.s

Encouraging Yourself

m. Taking Risks Wisely

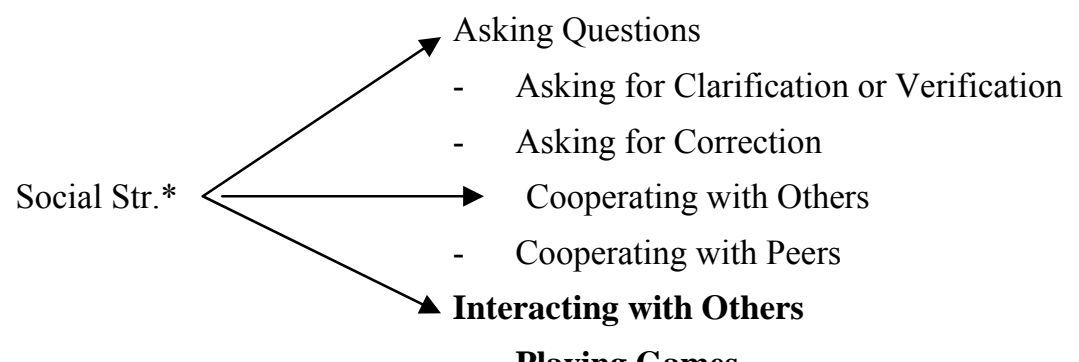

- Playing Games

- Having Fun with the New Language

- Asking more Knowledgeable Persons to Question Oneself 